Caligrama, Belo Horizonte, v. 22, n. 2, p. 61-81, 2017

\title{
Níveis de execução gráfica e alfabetismo no Brasil quinhentista
}

\section{Levels of graphic execution and literacy in sixteenth-century Brazil}

Ana Sartori Gandra

Universidade Federal da Bahia, Salvador, Bahia / Brasil anasartorii@hotmail.com

Resumo: $O$ estudo aqui apresentado tem como foco o alfabetismo no Brasil de finais de Quinhentos. O corpus utilizado é o dos livros produzidos durante a Primeira Visitação da Inquisição ao Brasil, nas Capitanias de Pernambuco, Itamaracá e Paraíba. As assinaturas e sinais não alfabéticos deixados pela população que ia depor perante o Tribunal são fonte para uma análise qualitativa, ou uma análise da "morfologia das assinaturas", como também é chamada. As assinaturas deixadas pelas testemunhas foram classificadas em dois níveis de execução gráfica: um médio, ou alto, e um baixo. Tais níveis têm relação com o grau de letramento dos escreventes e também com o perfil social desses indivíduos. Uma grande difusão do alfabetismo no Brasil de Quinhentos já havia sido atestada em uma análise quantitativa dos percentuais de assinantes e não assinantes nas fontes inquisitoriais. Observa-se aqui, com a análise dos níveis de execução gráfica das assinaturas, que haveria um acesso bastante variado às práticas de escrita

Palavras-chave: níveis de execução gráfica; assinaturas; século XVI.

Abstract: This study focuses on literacy in Brazil at the end of the sixteenth century. The corpus used is the books produced during the first visit of the Inquisition in Brazil, in Captaincies of Pernambuco, Itamaracá and Paraíba. The signatures and non-alphabetic signs left by the population that was called to testify before the Court are the source 
for a quantitative analysis, or an analysis of 'signatures morphology', as it is also called. The signatures left by witnesses were classified into two levels of graphic execution: a medium or high level of execution and a low level. Such levels are related to the level of literacy of the scribes and also to the social profile of these individuals. A large diffusion of literacy in Brazil in the sixteenth century had already been attested in a quantitative analysis of percentages of subscribers and non-subscribers in the inquisitorial sources. It is observed here, with an analysis of the levels of graphical execution of the signatures, that there was a wide variety of access to practices of writing

Keywords: levels of graphic execution; signatures; 16th century.

Recebido em: 30 de abril de 2017.

Aprovado em: 14 de agosto de 2017.

\section{A história da cultura escrita e os estudos do alfabetismo}

Em finais do século XX, após transformações que se deram na história da escrita e na do livro e da leitura, delineia-se uma história da cultura escrita, para a qual convergem esses dois campos de estudos, como também aquele da história da alfabetização ou do alfabetismo - como será aqui nomeado. Assim como a nova historiografia cultural procura abarcar a diversidade de práticas e objetos próprios aos diferentes povos, ao longo do tempo, uma perspectiva contemporânea da história da cultura escrita procura dar conta da diversidade de testemunhos das práticas de leitura e escrita que se constituíram nas diversas sociedades, inclusive daquelas mais cotidianas e dos escritos que retratam as variedades socialmente mais estigmatizadas da língua.

Com relação à história da escrita, observa-se que, se seus estudos, até recentemente, tinham como objetivo unicamente classificar e medir esse sistema enquanto instrumento de comunicação, sem tratar de qualquer implicação de seu uso nas sociedades que o empregaram ao longo do tempo, o que se observa atualmente, como afirma Castillo Gómez (2003, p. 95-96), é um projeto que transcende a visão da escrita enquanto mero sistema gráfico, procurando abordar suas distintas funções e suas consequentes práticas materiais, sempre em referência às 
respectivas sociedades históricas e tendo em conta que em cada momento a sociedade esteve formada por alfabetizados e analfabetos. Petrucci (1999) considera que toda investigação que almeje estudar as relações entre cultura escrita e sociedade deve ter em conta dois elementos: a difusão social da escrita, entendida como a capacidade de escrever e ler; e a função que a escrita em si mesma assume no âmbito de cada sociedade, e que cada tipo ou produto gráfico assume, em um ambiente cultural concreto que o produz e o emprega.

No âmbito dos estudos do alfabetismo, os quais igualmente convergiram para uma ampla história da cultura escrita, o período censitário pode ser tido como um divisor de águas. Com a instituição dos censos demográficos, encontram-se aferições globais sobre os níveis de escolarização das populações. Para o período pré-censitário, o historiador do alfabetismo deve buscar "séries homogêneas e continuadas de indicadores das habilidades individuais" (LANGELI, 1996, p. 93, tradução nossa). Nesse âmbito, os dados que têm sido largamente explorados são as assinaturas deixadas em registros de matrimônio e de batismo, em testamentos, livros de ata etc., uma vez que a capacidade para escrever o próprio nome é uma medida universal, que pode ser utilizada comparativamente nas diversas sociedades. Associado geralmente às séries de dados indicadores das habilidades de escrita, o método quantitativo de análise tem como objetivo atribuir percentuais e valores numéricos aos dados encontrados, contrastando, na história do alfabetismo, indivíduos capazes e incapazes de escrever ou simplesmente assinar.

Outro marco temporal, no que tange aos estudos quantitativos do alfabetismo, é o início da Época Moderna, momento em que as assinaturas passaram a ter registro obrigatório nos documentos. $\mathrm{Na}$ Inglaterra, na França e na Suécia, do século XVI ao XVII, começam a aparecer documentos assinados. Fraenkel ([s.d.]) relata que na França a assinatura se tornou obrigatória em 1554, quando Henrique II determinou aos notários que fizessem as partes contratantes assinarem, se elas o soubessem. Na Itália, as séries continuadas e sistemáticas de assinaturas são encontradas apenas a partir de 1806, quando a legislação napoleônica determinou que noivos e testemunhas assinassem as atas de casamento (LANGELI, 1996, p. 93-94). Em Portugal, Ribeiro da Silva comenta que, na região do Porto e seu entorno, não se encontram registros de assinaturas nos livros de registro paroquial anteriores ao século XVIII. Segundo o autor, tal situação é a mesma para quase toda a Espanha (RIBEIRO DA SILVA, 1986, p. 108). 
Quanto aos estudos de períodos anteriores aos das séries de assinaturas, Langeli (1996) avalia que o alfabetismo das épocas préestatísticas não é um objeto incognoscível: "não é mensurável em termos absolutos, mas se pode valorar seu sentido e sua qualidade mediante instrumentos interpretativos necessariamente distintos dos estatísticos, mas não por isso mais pobres ou superficiais" (LANGELI, 1996, p. 97, tradução nossa). O autor ressalta que a visão bipartida que aborda analfabetos $\mathrm{x}$ alfabetizados, fruto da análise com base em dados numéricos, não basta para se compreender o fenômeno, e que os limites entre os dois termos não são tão bem definidos a ponto de se permitirem divisões muito rígidas.

Ao abordar outro método de estudo do alfabetismo, o método qualitativo de análise, Langeli (1996) considera que a análise qualitativa não exclui o estudo das assinaturas, mas é preciso se tratar da melhor forma possível os testemunhos gráficos produzidos, tendo-se em vista o caráter de inscrições estandardizadas e simplificadas que elas têm. A respeito do período anterior à Época Moderna, quando não se encontram dados como as assinaturas, capazes de fornecer uma amostra "universal" ou representativa de forma global da sociedade, Langeli comenta que se encontra uma boa quantidade de textos autógrafos, com uma maior extensão e articulação, que seriam fontes ideais para uma análise qualitativa, permitindo "que os escreventes possam denominar-se autores de um texto e não executores de uma mera sequência de signos" (LANGELI, 1996, p. 99, tradução nossa).

Em uma linha de análise qualitativa, mas que não exclui a quantificação dos dados analisados, encontra-se um estudo de Petrucci (1978), que se debruça sobre um livreto de contas de Maddalena, analfabeta, dona de uma venda no bairro de Trastevere, em Roma. O livreto possui uma lista de registros de 1523 a 1537, deixados por credores e devedores ou por dependentes e representantes destes, nos quais constam pagamentos realizados, débitos contraídos e saldados para comprar itens para a venda, empréstimos e declarações de futuro saldo. Entre as 102 mãos que deixaram seu registro no livro, foram identificados por Petrucci dois tipos de escrita: a italiana de chancelaria, "a escrita dos cultos e dos ofícios públicos, daqueles que sabem o latim e dos eclesiásticos", e a mercantil, "escrita dos negócios e dos mercados, mas também das vendas e das tabernas, em suma das camadas mais baixas da sociedade alfabetizada" (PETRUCCI, 1978, p. 167, tradução nossa). 
Petrucci distinguiu, em cada um desses sistemas de escrita, gradações da capacidade de execução gráfica, divididas em três níveis: "pura", "usual" e "elementar de base".

Entre os escreventes que utilizaram a italiana de chancelaria, alguns apresentaram um nível "puro" de execução, com grande aderência ao modelo "normal" daquele sistema de escrita. Os seus registros possuíam um notável grau de homogeneidade, visível em todos os traços característicos da italiana de chancelaria: módulo médio, leve inclinação à direita, traçado delicado, escasso uso de ligamentos, " $\mathrm{f}$ " e "s" longos sem laço fechado, falsos ligamentos em "ct" e "st", uso de "et" e do "s" de forma maiúscula, uso normal do "r" cursivo reto que se liga só à esquerda. Quanto aos usuários do sistema de escrita da mercantil, classificados com um nível "puro" de execução, com um tipo de escrita que se poderia definir como profissional, vizinho a uma norma gráfica, encontram-se mãos que operam a escrita com certo domínio e sabem usar com desenvoltura o sistema abreviativo, os símbolos monetários e de contas. Essas mãos apresentaram um panorama gráfico heterogêneo, alternando-se módulos grandes e pequenos, ductus cursivo e semicursivo, curso fortemente inclinado e curso reto, abundância e escassez de ligamentos etc. Observam-se ainda formas variantes de algumas letras, como "e", "r", "f", "s" e "u/v".

Entre aqueles que utilizaram uma escrita descrita como itálica "usual", não se observa uma aderência segura a modelos "normais". A cursividade e a presença de ligamentos são, em geral, muito mais pronunciadas do que entre os escreventes do nível "puro" de execução. Em algumas mãos, vê-se uma influência mais forte da escrita mercantil nos frequentes ligamentos em sentido anti-horário, variação de traços simples e duplicados para o "d" e o "p", escasso uso de falsos ligamentos entre "ct", "st" etc. Entre os escreventes da mercantil "usual", o aspecto geral característico desse sistema de escrita se perdeu, seja por forte personalização da escrita, seja por excessiva cursividade, seja por inabilidade do escrevente. Os registros de escrita classificados como "elementar de base" italiana de chancelaria são, segundo Petrucci (1978), extremamente heterogêneos e de difícil caracterização. Distinguem-se, nesse grupo, executores mais inábeis de outros mais individualizados, provavelmente em fase de aprendizado da escrita. Aparecem evidentes influências da mercantil, variação do "r", uso frequente do "s" maiúsculo, presença de ligamentos com o "d", entre outras peculiaridades. Entre as 
mãos de "elementar de base" mercantil, notam-se escritas não apenas inábeis e hesitantes, mas também pobres, escassamente formadas de elementos auxiliares, como pontuações, sinais diacríticos, abreviaturas, símbolos técnicos; o uso de ligamentos é também pouco frequente e ocasional. Há uma forte tendência à personalização e uma escassíssima caracterização estilística.

A partir dos níveis de execução gráfica analisados, Petrucci (1978) realizou uma caracterização social dos escreventes, reunindo-os em oito grupos, de acordo com sua profissão ou posição social. O grupo de mais alto nível gráfico e ortográfico é composto por dois religiosos e o único notário presente. Os religiosos escrevem em uma elegante itálica pura e o notário em uma estilizada itálica usual; Petrucci supõe que os três conhecessem e utilizassem frequentemente o latim como língua escrita. Todos eles não escreveram por si, mas a pedido de outras pessoas. Outro grupo reuniu oito pessoas pertencentes a famílias de algum relevo, cinco deles usuários da escrita itálica (três, em itálica pura, dois, em usual) e três da escrita mercantil; dois deles mostraram conhecer o latim. Quatro corretores e cobradores de contas de terceiros figuraram em outra categoria, revelando, todos, bom nível de expressão gráfica; um utiliza uma bela itálica pura, um, uma mercantil pura e dois, uma itálica usual; um deles demonstrou conhecer o latim. Cinco escreventes compuseram um quarto grupo, de titulares de estabelecimentos comerciais. Três deles escreveram em pura mercantil, um, em mercantil usual e um, em itálica usual.

A categoria de profissões mais representada no livro foi a de funcionários de empresas comerciais: foram 28 indivíduos, entre criados, escrivães, contadores, copeiros, aprendizes de diversas companhias grandes e também menores. Vinte integrantes desse grupo escreveram em mercantil e oito em itálica, sendo que nenhum escreveu em itálica pura, ou em elementar de base mercantil. Quase todos escreveram com relativa correção ortográfica, operaram com desenvoltura símbolos técnicos para indicar as moedas e recorreram a frequentes abreviaturas; nenhum demonstrou conhecer o latim. Outro grupo compôs-se por dez artesãos e lojistas e ainda seus funcionários, pessoas de diferentes níveis sociais e culturais. Apenas um fez uso de um elementar de base do tipo itálico; os outros nove escreveram em mercantil, três destes em uma elegante mercantil pura. Nenhum deles demonstrou conhecer o latim. Os fornecedores e transportadores de mercadorias somaram doze escreventes. Onze deles utilizaram a mercantil, oito em elementar de 
base, três em usual. Todos escreveram textos breves e incorretos, nenhum demonstrou conhecer o latim; apenas seis demonstraram conhecer símbolos técnicos para as moedas. Um último grupo foi formado por quatro queijeiros, todos escreventes em elementar de base mercantil, demonstrando grande dificuldade no uso da escrita. Para além dos 102 escreventes quantificados, constatou-se a presença de seis analfabetos, que delegaram a escrita no livreto a outrem: dois entregadores, um queijeiro, um taverneiro, o irmão de um lojista e uma mulher, Maddalena.

Diante dos resultados apresentados, que revelam uma difusão da escrita, em diferentes níveis de execução e sistemas, em diversificados estratos sociais, e dando por certa a inexistência de uma organização escolar elementar homogênea e generalizada na Roma da primeira metade do século XVI, Petrucci (1978, p.190-191, tradução nossa) considera "evidente que o ensino da escrita ocorria, fora de qualquer legislação comum, em modos e formas diversas segundo as circunstâncias, dos níveis culturais e sociais dos indivíduos, das exigências econômicas de grupo ou ambiente". Para as classes média e baixa da sociedade, considera que haveria o acesso a escolas urbanas comuns, com professores elementares, privados de qualquer sanção oficial ou função pública. Sobre tais escolas, Petrucci (1978) afirma que se sabe muito pouco, além de estarem localizadas em Roma, serem muito escassas e mal organizadas. $\mathrm{O}$ autor pressupõe ainda outro tipo de ensino elementar centrado nas duas unidades fundamentais da sociedade urbana da época: o comércio e a família, sabendo-se que, nesses ambientes, o membro mais velho ou mais capaz poderia dar aos outros, sobretudo aos meninos, lições de leitura, de escrita e de contas. Em tais contextos se poderia verificar o aprendizado em qualquer tipo de escrita e a qualquer nível, mas, como pontua Petrucci, "certamente é no ambiente doméstico ou da pequena loja artesã que se realizava o ensino daquele elementar de base de tipo mercantil que se vê na escrita dos mais humildes semialfabetizados da época" (PETRUCCI, 1978, p.192, tradução nossa).

\section{Níveis de execução gráfica no Brasil quinhentista}

O primeiro século de colonização brasileira nos deixou como legado os livros produzidos na primeira Visitação do Tribunal da Inquisição ao Brasil, os quais vêm se revelando uma preciosa fonte para os estudos da cultura escrita no país no período pré-censitário. 
De 1593 a 1595, o Tribunal itinerante do Santo Ofício visitou as Capitanias de Pernambuco, de Itamaracá e da Paraíba. O notário do Santo Ofício deixou registrados nos livros os depoimentos de 348 indivíduos que compareceram perante à mesa do Tribunal para denunciar crimes contra a fé católica ou para confessar as próprias culpas. Ao final do depoimento, era solicitado à testemunha que assinasse o livro, como forma de confirmar e validar o depoimento prestado. Nem todos, porém, seriam capazes de fazê-lo, já que parte dos que depunham não sabiam assinar. Alguns inscreviam, no lugar do nome, uma cruz. Outros pediam ao notário que por eles assinasse, declarando sua inaptidão.

Dos 348 indivíduos que compareceram à mesa do Tribunal para testemunhar, tendo seu depoimento registrado nos livros produzidos nas capitanias citadas, 263 foram capazes de deixar seu nome escrito de próprio punho e 85 não o foram. Para além do alto percentual de assinantes, observa-se uma grande disparidade na capacidade de assinar entre homens e mulheres: enquanto $92 \%$ dos homens assinaram seu testemunho, $93 \%$ das mulheres não o fizeram. Quanto aos níveis de alfabetismo distribuídos entre os diversos estratos sociais, da elite colonial em direção ao povo, em linhas gerais, observa-se um decréscimo da capacidade de assinar. Vê-se, porém, que não há grande disparidade entre os percentuais de assinantes entre integrantes da mais alta elite colonial - os senhores de engenho, que tiveram $86 \%$ de assinantes - e trabalhadores de pequenos ofícios, integrantes do povo, $79 \%$ deles assinantes. Apenas o grupo dos escravos depoentes apresentou um resultado divergente, como seria de se esperar: foram apenas dois os escravos presentes, nenhum deles assinante. ${ }^{1}$

Os resultados encontrados sobre os percentuais de assinantes e não assinantes se confirmam e se aprofundam quando olhamos detidamente para as assinaturas e outros sinais não alfabéticos deixados pelas testemunhas nos livros inquisitoriais. É essa a tarefa que empreenderemos aqui, em uma análise qualitativa dos dados encontrados nas fontes inquisitoriais, que tem inspiração nos estudos citados de Petrucci (1978) sobre níveis de execução gráfica na Roma quinhentista, aqui reestruturados para melhor se adequar às especificidades dos dados

\footnotetext{
${ }^{1}$ Um estudo quantitativo pormenorizado das assinaturas registradas nas fontes inquisitoriais quinhentistas referentes às Capitanias de Pernambuco, Itamaracá e Paraíba encontra-se em Gandra (2016). Estudos sobre dados quinhentistas referentes à Capitania da Bahia encontram-se em Lobo e Oliveira (2012, 2013).
} 
analisados. Diferentemente do estudo de Petrucci, que aborda escritos de maior extensão, nos debruçamos sobre assinaturas, dados mais restritos, que não permitem, por exemplo, definirem-se quais os tipos de escrita utilizados, ou delimitarem-se com precisão três níveis de execução. Os registros de escrita encontrados nos livros da Inquisição foram divididos, assim, em dois níveis de execução gráfica: um nível médio/alto e um nível baixo.

Entre as características da escrita de redatores classificada como um nível médio ou alto, observa-se segurança e desenvoltura na execução, traçado regular, uso de ornamentação, com serifas e laçadas, uso adequado de elementos auxiliares, como sinais diacríticos, abreviaturas e pontuações e bom alinhamento das letras. Podem-se encontrar ou não ligações e abreviaturas. Em alguns registros, nota-se uma mais forte personalização ou excessiva cursividade, o que geralmente ocasiona letras malfeitas.

As características dos escritos agrupados como um nível baixo de execução gráfica são: escritas bastante inábeis e hesitantes, letras traçadas com dificuldade, módulo maior que o normal, irregularidade no traçado. Por vezes, a dificuldade na escrita é tamanha, que apenas se consegue produzir poucas letras, com um traçado que pode ser bastante diferente do traçado usual das letras. Entre os que possuem esse nível de execução gráfica, imagina-se que se encontrem aqueles que, em sua maioria, não saberiam de fato escrever, apenas assinar, com dificuldade, o nome.

\subsection{Assinaturas com nível médio ou alto de execução gráfica}

Os depoentes com um nível médio ou alto de execução gráfica das suas assinaturas apresentam destreza ao segurar a pena, o que é perceptível pelo traçado não vacilante, pela abundância de laçadas ligadas ou não às letras, e outros ornamentos, como cruzes, traços com pontos, sublinhados e outros traços. É o que se nota nos exemplos a seguir:2

\footnotetext{
${ }^{2}$ A análise das assinaturas e sinais não alfabéticos foi realizada a partir das edições fac-similares do Quarto livro das denunciações da primeira visitação da Inquisição ao Brasil e do Terceiro livro das confissões da primeira visitação da Inquisição ao Brasil, disponíveis no site do Arquivo Nacional da Torre do Tombo, onde se encontram depositados os originais dos referidos livros (cf. QUARTO..., 1593-1595; TERCEIRO..., 1594-1595). Para que as legendas das imagens inseridas ao longo do texto fiquem mais limpas, serão informados apenas a primeira palavra do título e o número da folha do manuscrito em que as assinaturas se encontram.
} 


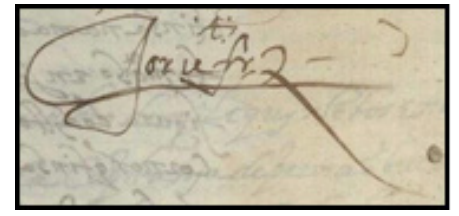

Assinatura de Jorge Fernandes, clérigo (QUARTO..., f. 08r).

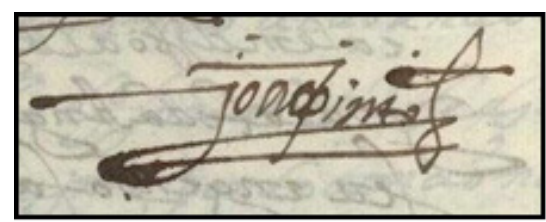

Assinatura de João Pinto (QUARTO..., f. 10r).

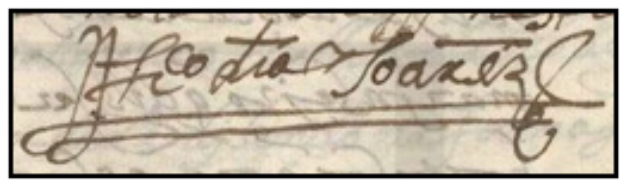

Assinatura de Francisco Soares, mercador (QUARTO..., f. 13r).

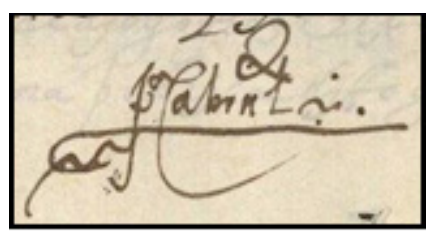

Assinatura de Pero Cabral, clérigo (QUARTO..., f. 19v).

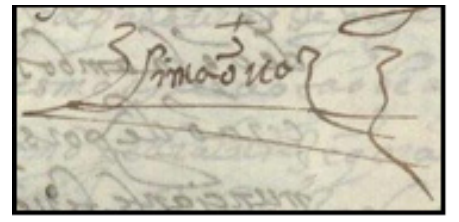

Assinatura de Simão Vaz, lavrador (QUARTO..., f. 08v).

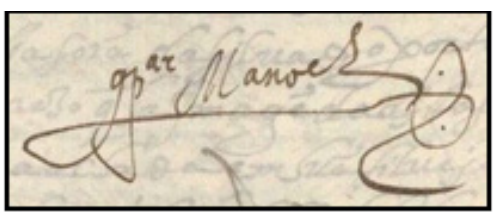

Assinatura de Gaspar Manuel, clérigo (QUARTO..., f. 12r).

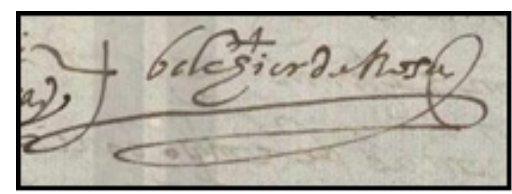

Assinatura de Belchior da Rosa, que vivia de sua fazenda (QUARTO..., f. 16v).

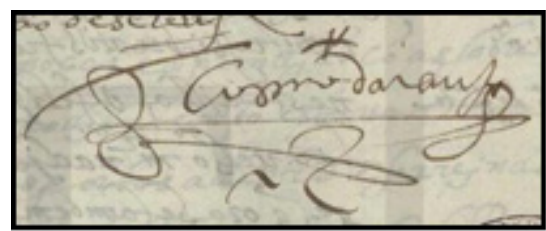

Assinatura de Cosme de Araújo (ocupação não declarada) (QUARTO..., f. 24v). 
A cruz é encontrada com bastante frequência nessas assinaturas, sendo preferivelmente colocada sobre o nome, mais ao centro. ${ }^{3}$ Não raro, é ornada por pontos em seus ângulos. Às vezes aparece solta, às vezes, unida a um traço (como se vê na assinatura de Gaspar Manuel), ou, mais raramente, a uma letra (como ocorre com o nome de Francisco Dias Soares).

A segurança e a desenvoltura no traçado que se observam nas assinaturas com nível médio ou alto de execução gráfica nem sempre se encontram aliadas à legibilidade. As letras podem, por vezes, se apresentar ilegíveis, influindo muito para isso o estilo das assinaturas; enquanto algumas possuem um estilo mais "limpo", um traçado delicado e esmerado, geralmente aliado a letras bastante legíveis, outras têm um estilo mais desprendido, um traçado mais livre e não tão bem-desenhado, que podem, por isso, tornarem-se, em alguns casos, ilegíveis.

\subsection{Assinaturas com nível baixo de execução gráfica}

Os depoentes que apresentaram um nível baixo de execução gráfica das suas assinaturas exibem claramente gradações na capacidade de escrever o nome. Alguns revelam grande dificuldade para desenhar algumas poucas letras, cujo traçado não raro finda por ser irreconhecível. O português Gonçalo Ferreira, lavrador de mandioca que teria sido também alfaiate, faz, em seu nome, um ' $\mathrm{g}$ ' cujo bojo é interrompido antes de se fechar e põe um 'o' sobrescrito, com traçado mais semelhante ao de um ponto que propriamente um círculo. Após essas, há duas letras que se infere que sejam "f" e "r", a primeira constituída apenas por uma haste inclinada e um pequeno traço na parte superior e a segunda por um traço com duas ondulações. Sobre esta, há provavelmente um "a", constituído por um bojo de traço tremido complementado por um pé

\footnotetext{
${ }^{3}$ Fraenkel ([s.d.]), em um estudo da história das assinaturas, comenta que a referência a Deus era uma das instâncias convocadas para a validação do documento escrito, na Idade Média. A referência a Deus se expressava através de invocações diretas, como "In nomine Patris et Filii et Spiritus Sancti", ou por marcas menos diretas, como as cruzes ou os chrismons. Para Fraenkel, o uso da cruz nas assinaturas, encontrada junto aos nomes dos letrados ou ainda sozinha, utilizada por indivíduos analfabetos, no lugar das assinaturas, era um sinal que estaria representando simbolicamente a função de um "nome coletivo", conferido pelo cristianismo: "não somos todos filhos de Deus?" (FRAENKEL, [s.d.], tradução nossa).
} 
mal ligado a ele. Igualmente malfeitas são as assinaturas do sapateiro João Fernandes, do carreiro Pero João e do aprendiz de ferreiro Afonso Rodrigues, alguns dentre outros tantos cujas assinaturas são visivelmente traçadas com grande dificuldade.

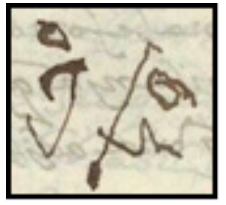

Assinatura de Gonçalo Ferreira, lavrador de mandioca (QUARTO..., f. 79r).

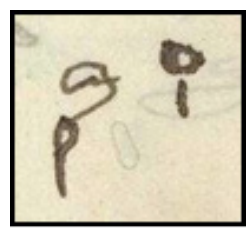

Assinatura de Pero João, carreiro (QUARTO..., f. 233r).

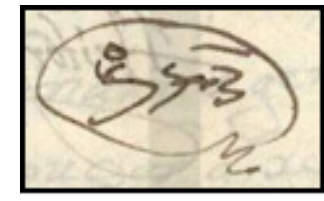

Assinatura de João Fernandes, sapateiro (QUARTO..., f. 217v).

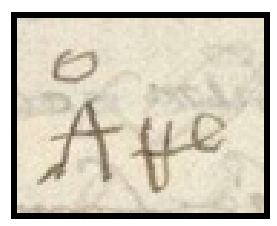

Assinatura de Afonso Rodrigues, aprendiz de ferreiro (QUARTO..., f. 253v).

Outras testemunhas com um nível baixo de execução gráfica não parecem apresentar tanta dificuldade ao segurar a pena. Revelam mais segurança no traçado, uma escrita mais corrente, geralmente também com mais letras, mesmo que a abreviatura de nomes seja marca bastante presente. São exemplos desses: Francisco Barbosa da Silva, filho de gente da governança da Ilha de São Miguel, que escreve em sua assinatura seu nome completo; Antônio Fernandes, aprendiz de oleiro, que, apesar de abreviar seu nome, escreve-o com letras relativamente bem-traçadas; o mulato Manuel de Leão, que tem o primeiro nome legível e peca particularmente no traçado do "de"; e ainda Manuel Franco, que demonstra maior capacidade para a escrita até mesmo na abreviatura do seu primeiro nome, feita com desenvoltura, traçando-se o "e" ligado a uma laçada que parte de baixo do nome. 


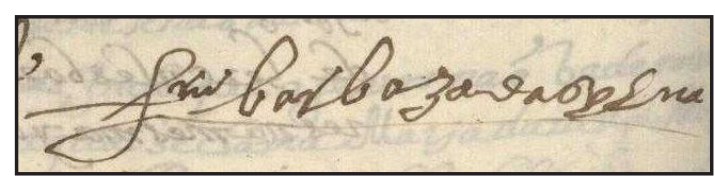

Assinatura de Francisco Barbosa da Silva, filho de homem da governança (QUARTO..., f. 144v).

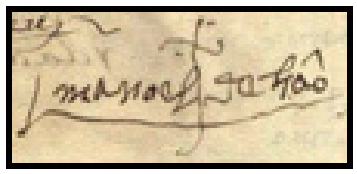

Assinatura de Manuel de Leão, vaqueiro e esteireiro (TERCEIRO..., f. 11r).

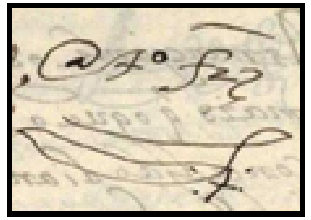

Assinatura de Antônio Fernandes, aprendiz de oleiro (QUARTO..., f. 232v).

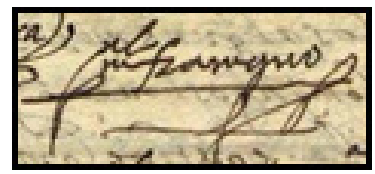

Assinatura de Manuel Franco, trabalhador de enxada e foice (TERCEIRO..., f. 79r).

Encontram-se ainda ornamentos nas assinaturas, embora de apresentação bem mais tímida; veem-se raras laçadas e traços mais frequentes, acima, abaixo e dos lados do nome. Por vezes, os traços compõem uma cercadura quadrada ou arredondada para o nome, como se vê na assinatura de Salvador Jorge ou na assinatura de Antônio Gonçalves.

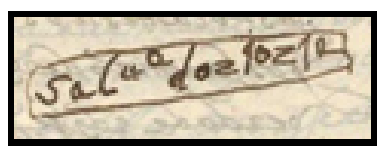

Assinatura de Salvador Jorge (ocupação não declarada) (QUARTO..., f. 91v).

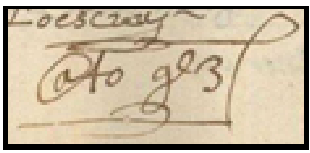

Assinatura de Antônio Gonçalves, purgador de açúcar (QUARTO..., f. 113v). 


\subsection{Caracterização dos escreventes}

Ao ser avaliado o perfil social dos escreventes, observa-se uma gritante relação entre o nível de execução gráfica e o sexo dos assinantes. Entre os homens, 84\% apresentaram um nível médio ou alto de execução; entre as poucas mulheres assinantes (apenas cinco), nenhuma foi capaz de assinar bem o seu nome. Maria de Heredo, mameluca de 21 anos, casada com o alcaide-mor da Capitania de Pernambuco, conseguiu traçar apenas um "M" e outra letra ilegível, cujo traçado se assemelha ao de um "p". Igualmente rudimentar é a assinatura de Caterina Fernandes, mameluca casada com um escrivão, que reduz sua assinatura a um "f" de linhas trêmulas. Maria Lopes, viúva de homem da governança, também dono de engenho, esforçou-se para escrever nome e sobrenome em sua assinatura. Desenhou um "m" virado de ponta-cabeça e um "a" mal traçado sobrescrito, em seguida as letras "l, o, p" e uma letra que parece um "z" com um traço trêmulo sobre ela, provavelmente usado como sinal abreviativo. Maria de Faria, portuguesa, que declarou viver, com seu marido, por sua indústria, escreveu "maria" com a letra "a" semelhante a um "e" e a letra "i' com a haste torta e apagada e um traço horizontal, também apagado, que confere a essa letra uma imagem semelhante a um " $t$ "; o nome foi encerrado por uma cercadura feita com linha trêmula. A assinante seguinte é a que consegue executar com maior destreza seu nome, ainda que com um traçado hesitante e letras mal alinhadas. Trata-se de Joana d'Albuquerque, mameluca, filha de Jerônimo d'Albuquerque, homem dos "principais da terra", que traça com clareza as letras do seu primeiro nome, antecedido pela palavra "dona". Destacam-se as letras "d" e o primeiro "n" por estarem mal escritas.

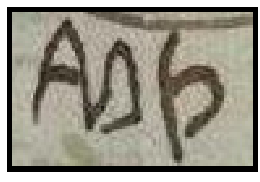

Assinatura de Maria de Heredo (QUARTO..., f. 22r).

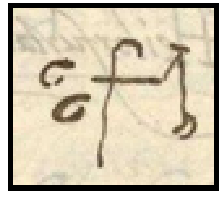

Assinatura de Caterina Fernandes (QUARTO..., f. 246v). 


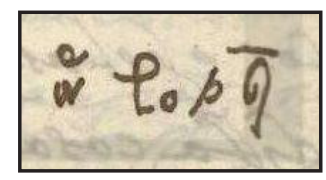

Assinatura de Maria Lopes (QUARTO..., f. 84v).

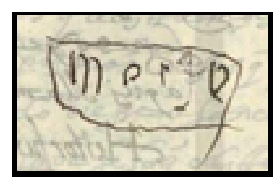

Assinatura de Maria de Faria (QUARTO..., f. 70r).

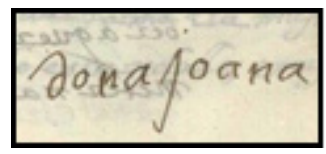

Assinatura de Joana d'Albuquerque

(QUARTO..., f. 133r).

O exame da morfologia das assinaturas femininas confirma o que se constatou através da análise quantitativa de mulheres assinantes, indicando um acesso extremamente restrito destas às práticas de escrita, sendo que, nas raras circunstâncias em que elas revelaram algum acesso ao letramento, mostraram um nível muito baixo de execução gráfica, o que seria provavelmente reforçado pela falta de prática do conhecimento de escrita adquirido.

A média geral dos assinantes que apresentaram um nível médio ou alto de execução gráfica foi $83 \%$. Entre os diversos grupos sócioocupacionais que depuseram nos livros inquisitoriais, apresentaram altíssimos percentuais dos níveis de execução médio ou alto, ficando acima da média geral: o clero, com $90 \%$ de assinantes com nível alto de execução; os burocratas, com 94\%; os lavradores, com 95\%; os mercadores, os liberais e os senhores de engenho, todos os três grupos com $100 \%$ de assinantes com nível médio/alto de execução; e ainda o único homem do mar assinante. Os estratos populacionais que tiveram mais redatores com um nível baixo de execução gráfica foram assalariados, artesãos e pequenos ofícios. Entre os assalariados, 71\% dos indivíduos executaram suas assinaturas com um nível médio/alto; entre os artesãos a taxa foi de $64 \%$ e entre os pequenos ofícios, $62 \%$. Os assalariados que não executaram bem suas assinaturas foram dois feitores, dois purgadores de açúcar, um mestre de açúcar e um mareante. Vê-se que todos eles, ainda que se enquadrem em um nível baixo de execução gráfica, revelam já alguma desenvoltura na escrita. Entre os 
artesãos que não assinaram bem, se encontram quatro sapateiros, maioria em um total de cinco sapateiros assinantes; um único carpinteiro entre sete carpinteiros assinantes; um oleiro e um aprendiz de oleiro, únicos na profissão a testemunhar; e um aprendiz de ferreiro, enquanto o outro ferreiro testemunhante assinou bem. Entre os pequenos ofícios, assinaram com um nível baixo de execução gráfica: uma testemunha que declarou servir de soldada, um vinhateiro, um pescador, um pedreiro, um trabalhador de enxada e foice, um vaqueiro que já foi esteireiro, e ainda três carreiros, maioria entre os quatro carreiros assinantes.

\subsection{A cruz e outros sinais não alfabéticos}

As testemunhas masculinas que não sabiam assinar deixavam, ao final do seu testemunho, um sinal não alfabético em lugar do nome, sendo a cruz o sinal largamente utilizado. $\mathrm{O}$ seu traçado era bastante variado, o que por vezes reflete uma maior ou menor destreza do redator. Algumas apresentavam o traço grosso, como a cruz de Diogo Gonçalves, dono de engenho; outras, um traço mais fino, como é o caso da cruz do soldado Rodrigo Sequeira. Veem-se ainda diferentes traçados, cruzes com traços simples, uma cruz com um traço em cima (feita por Francisco Gonçalves), cruzes com as extremidades barradas (feita por Antônio da Concepção), cruzes com pontos nos ângulos (como a de Domingos Lopes), com as extremidades curvas (de Pero Mendes).

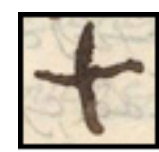

Cruz de Diogo Gonçalves, dono de engenho (QUARTO..., f. 28v).

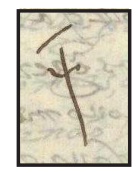

Cruz de Francisco Gonçalves, grumete de navegação (QUARTO..., f. 51r).

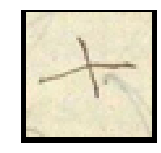

Cruz de Rodrigo Sequeira, Soldado (QUARTO..., f. 43r).

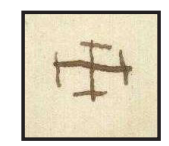

Cruz de Antônio da Concepção, escravo (QUARTO..., f. 81r). 


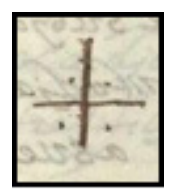

Cruz de Domingos Lopes, feitor (QUARTO..., f. 99r).

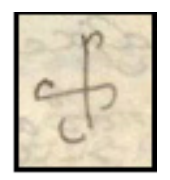

Cruz de Pero Mendes, Pescador (QUARTO..., f. 210v).

O comportamento das testemunhas femininas quando não eram capazes de assinar divergia bastante do comportamento masculino. Enquanto os homens que não sabiam escrever seu nome faziam, praticamente todos, em lugar da assinatura alfabética, a cruz ou outro sinal, as mulheres declaravam ao notário não saber assinar e solicitavam que ele assinasse em seu lugar. Nos livros inquisitoriais da Primeira Visitação às Capitanias de Pernambuco, Itamaracá e Paraíba, entre os 63 indivíduos que declararam não saber assinar e pediram ao notário para assinar em seu lugar, 62 eram mulheres, apenas um era homem, o qual não assinou declarando estar cego. Esse resultado, em que se contrasta a atitude de homens e mulheres diante da incapacidade de assinar, não é, seguramente, uma coincidência.

Dados recolhidos por Marquilhas (2000, p. 116) em depoimentos da Inquisição em Portugal do século XVII, a fazem considerar o comportamento de homens e mulheres que não sabiam escrever como um verdadeiro "ritual signatário", uma vez que os homens, com raras exceções, assinavam de cruz quando não podiam assinar, as mulheres nunca assinavam só "de cruz", pois, mesmo que fizessem a cruz, o notário assinava ao lado desta. A autora cita ainda uma elucidativa passagem de um dos textos das comissões escritas pelos inquisidores, com instruções aos funcionários do Santo Ofício, em que se diz: “[...] não sabendo alguma das testemunhas assinar, assinara por ella a seu rogo o escrivão desta diligencia, sendo mulheres" (ANTT, Inquisição de Évora, liv. 233, Cadernos do Promotor, fls. 75r-77r apud MARQUILHAS, 2000, p. 116).

Contrariando esse "ritual signatário", registrou-se nos livros do Santo Ofício aqui analisados o depoimento de uma única mulher que utilizou um sinal não alfabético em lugar do seu nome: Joana Afonso, negra de 40 anos, natural de São Tomé e Príncipe, casada com alfaiate, mulato, que deixou o desenho de uma cruz no livro da Inquisição: 


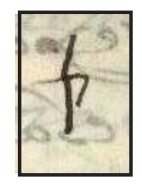

Cruz de Joana Afonso (QUARTO..., f. 216r).

Os raros sinais não alfabéticos diferentes da cruz que se registraram foram deixados por homens. Dois deles tinham a profissão de vaqueiro: o português Luís Gomes, de 60 anos, e Francisco Cortes, italiano, que tinha 40 anos de idade. Além deles, também desenhou um sinal não alfabético João Paris, espanhol de 30 anos, bombardeiro no Forte do Cabedelo, na Barra da Paraíba.

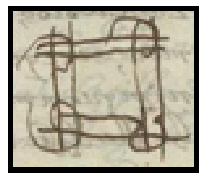

Sinal de Luís Gomes, vaqueiro

(QUARTO..., f. 143r).

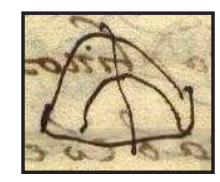

Sinal de Francisco

Cortes, vaqueiro (TERCEIRO..., f. 17v).

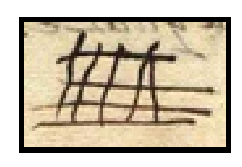

Sinal de João de Paris, bombardeiro (TERCEIRO..., f. 105v).

Os sinais desenhados por esses depoentes parecem signos motivados, semelhantes aos sinais analisados por Ribeiro da Silva (1986) de documentos do século XVI e XVII da região do Porto, em Portugal, que lembravam, muitas vezes, elementos do ofício dos assinantes, como a tesoura, no caso do alfaiate; o machado, no caso do lenhador; e o esquadro, no caso do carpinteiro. Os sinais utilizados por Luís Gomes e Francisco Cortes podem ser, ao que parece, relacionados à sua profissão de vaqueiro, pois guardam semelhança com a imagem de um curral. O desenho do bombardeiro João de Paris estará provavelmente representando a imagem de um forte, também relacionada a seu ofício. 


\section{Considerações finais}

A medição de níveis de alfabetismo nas fontes inquisitoriais revela altos percentuais de indivíduos assinantes nas Capitanias de Pernambuco, Itamaracá e Paraíba, em fins do século XVI. A difusão da escrita que tais dados indicam, restrita aos homens, é complexificada quando são analisados os níveis de execução gráfica das assinaturas deixadas pela população. Se entre homens do clero, burocratas, lavradores, mercadores, liberais e senhores de engenho exibem-se altíssimos percentuais de um nível médio/alto de execução gráfica, que pode ser associado a um grau mais elevado de letramento dos assinantes, entre escreventes assalariados, artesãos e trabalhadores de pequenos ofícios, sobretudo nos dois últimos grupos, já se encontra uma parcela significativa de indivíduos que apresentaram um nível baixo de execução gráfica, que pode ser associado a graus bastante incipientes de letramento e, em muitos casos, ao analfabetismo.

Dos resultados encontrados, ao menos duas considerações relevantes podem ser feitas. A primeira é a constatação de que seria menor o número de indivíduos que sabiam, de fato, ler e escrever, do que os percentuais de assinantes revelam. Esse aspecto já é bastante conhecido nos estudos sobre o alfabetismo e vem sendo levado em conta nas análises quantitativas. Como afirma Chartier (1991), as assinaturas são "indicadores culturais macroscópicos, compósitos, que não medem exatamente nem a difusão da capacidade de escrever, mais restrita do que os números indicam, nem a da leitura, que é mais extensa" (CHARTIER, 1991, p. 113-114). Assim, a porcentagem de assinantes pode indicar muito globalmente o limite de familiaridade com a escrita alcançado por determinada sociedade, mas não pode ser considerada como medida direta de uma competência cultural particular.

A segunda constatação a se fazer vai ao encontro das considerações de Petrucci (1978), a partir de seu estudo sobre o alfabetismo na Roma quinhentista. Os níveis de execução baixos entre as camadas mais baixas da população revelam, provavelmente, variadas formas de acesso às práticas de leitura e escrita, que vão, certamente, além dos muros dos colégios jesuítas. Muito poucas informações se têm também, no caso brasileiro, sobre escolas não oficiais ou sobre o ensino não escolarizado; sabe-se, porém, que existiram, e nos próprios depoimentos prestados à Inquisição portuguesa se encontram referências a mestres leigos, não vinculados à Companhia de Jesus ou outra ordem religiosa, que tinham 
"escolas particulares" de primeiras letras. Pode-se inferir, finalmente, que a existência de um ensino, bastante elementar, no ambiente doméstico e de trabalho pode justificar o significativo número de assinantes entre as camadas mais populares, que possuiriam, muitas vezes, níveis baixos de aquisição das práticas de leitura e escrita.

\section{Referências}

ARQUIVO NACIONAL DA TORRE DO TOMBO (ANTT). Site do ANTT. Lisboa: ANTT, 2005. Atualização diária. Disponível em: $<$ http:// antt.dgarq.gov.pt> $>$. Acesso em: 11 set. 2012.

CASTILLO GÓMEZ, A. Historia de la cultura escrita: ideas para el debate. Revista Brasileira de História da Educação, Maringá, n. 5, p. 93-124, jan.-jun. 2003.

CHARTIER, R. As práticas de escrita. In: ARIÈS, P.; CHARTIER, R. (Org.). História da vida privada: da renascença ao século das luzes. São Paulo: Companhia das Letras, 1991.p.112-161.

FRAENKEL, B. A assinatura contra a corrupção do escrito. In: BOTTÉRO, J. et al. Cultura, pensamento e escrita. São Paulo: Ática, 1995. p. 81-99.

FRAENKEL, B. La signature, moteur de l'évolution du nom de famille en Occident. La Aventure des Écritures. [s.d.]. Disponível em: <http:// classes.bnf.fr/ecritures/arret/signe/signature/07.htm>. Acesso em: 21 jun. 2015.

GANDRA, A. S. Pela pena do Santo Ofício: difusão social da escrita nas capitanias de Pernambuco, Itamaracá e Paraíba em finais Quinhentos. 2016. 885 p. Tese (Doutorado em Língua e Cultura) - Instituto de Letras, Universidade Federal da Bahia, Salvador, 2016. 3 v.

LANGELI, A. B. Historia del alfabetismo y método cuantitativo. Signo - Revista de Historia de la Cultura Escrita, Alcalá de Henares, n. 3, p. 87-106, 1996.

LOBO, T.; OLIVEIRA, K. Ainda aos olhos da Inquisição: novos dados sobre níveis de alfabetismo na Bahia em finais de Quinhentos. In: ÁlVAREZ, R.; MARTINS, A. M.; MONTEAGUDO, H. et al. (Org.). Ao sabor do texto: estudos dedicados a Ivo Castro. Santiago de Compostela: Universidade de Santiago de Compostela, Servizo de Publicacións e Intercambio Científico, 2013. p. 10-25. 
LOBO, T.; OLIVEIRA, K. Aos olhos da Inquisição: níveis de alfabetismo na Bahia em finais de Quinhentos. In: MATTOS E SILVA, R. V., OLIVEIRA, K., AMARANTE, J. (Org.). Várias navegações: português arcaico, português brasileiro, cultura escrita no Brasil, outros estudos. Salvador: EDUFBA, 2012. p. 36-56.

MARQUILHAS, R. A faculdade das letras: leitura e escrita em Portugal no séc. XVII. Lisboa: Imprensa Nacional; Casa da Moeda, 2000.

PETRUCCI, A. Alfabetismo, escritura, sociedad. [S.1.]: Gedisa Editorial, 1999.

PETRUCCI, A. Scrittura, alfabetismo ed educazione gráfica nella Roma del primo cinquecento: da um libretto di conti di Maddalena Pizzicarola in Trastevere. Scrittura e Civilità, Firenze, n. 2, p.163-207, 1978.

QUARTO livro das denunciações da primeira visitação do Santo Ofício da Inquisição do Brasil, a qual fez o licenciado Heitor Furtado de Mendonça, por especial comissão de Sua Alteza. [S.1.]: [s.n.], 15931595. 355 f. Edição fac-similada. Disponível em: < http://digitarq.dgarq.gov. pt/viewer?id=2318686> . Acesso em: 30 maio 2011. (A informação da data 1593-1594 está equivocada no site do ANTT).

RIBEIRO DA SILVA, F. A alfabetização no Antigo Regime: o caso do Porto e da sua região (1580-1650). Revista da Fac. de Letras, História, Porto, s. 2, v. 3, p. 101-163, 1986.

TERCEIRO livro das reconciliações e confissões da primeira visitação do Santo Ofício da Inquisição do Brasil, a qual fez o licenciado Heitor Furtado de Mendoca, por especial Comissão de Sua Alteza. \{S.1.]: [s.n.], 1594-1595. 247 f. Microfilme. Disponível em: <http://digitarq.dgarq.gov.pt/ details?id=2318684 $>$. Acesso em: 30 maio 2011. 